\title{
Development and prospect of environmental treatment and ecological restoration of closed coal mines
}

\author{
Guichuan Qiao ${ }^{1}$, Song Du ${ }^{2, *}$, Wei Liu ${ }^{1}$, Zihao Luo $^{1}$, Zishen mou ${ }^{1}$ \\ ${ }^{1}$ State Key Laboratory of Geohazard Prevention and Geoenvironment Protection (Chengdu University of Technology), Chengdu, 610059, \\ China; \\ ${ }^{2}$ General Prospecting Institute, China National Administration of Coal Geology, Beijing, 100039, China.
}

\begin{abstract}
The exploitation of coal mine resources has greatly contributed to China's economic development, but it has also caused damage to the surrounding ecological environment. With the adjustment and optimization of the national energy structure, many small or unqualified mines have been closed in recent years. Thus, the environmental treatment and ecological restoration of these closed coal mines need to be carried out urgently. In this study, the causes of closed coal mines are analyzed from the perspective of macro policy. Then, the key technical difficulties of comprehensive and systematic restoration and treatment of geological and ecological problems are discussed from multiple perspectives. Finally, the successful restoration and treatment cases of closed coal mines locally and globally are showed. The findings of this study provide ideas and methods for ecological environment restoration and management of closed coal mines.
\end{abstract}

\section{Introduction}

"Rich coal, poor oil, and less gas" are the basic characteristics of China's energy structure. Coal occupies and will remain in a dominant position in the country's energy system for a long time. In China, the main use of coal is for power generation. However, with the continuous development of wind, water, and solar power generation and other technologies, infrastructure construction is constantly improving. Consequently, the country's coal industry has entered a new period of adjustment-coal supply-side structural reform, de-capacity, limited use, and economic development of the new normal will accelerate the integration and closure of coal mines. ${ }^{[1]}$ The number of coal mines in China was reduced from 37000 at the beginning of this century to 5268 in 2019 . In the past three years, the small coal mines with an annual output of fewer than 300,000 tons have been further combed and classified for disposal to increase the elimination and closure. The proportion of large coal mines is expected to be over $70 \%$ by $2022 .^{[2]}$ The coal mining efficiency is greatly improved, but at the same time, the environmental control and ecological restoration of closed coal mines are brought about.

The environmental control of closed coal mines has become the focus of ecological environment work in China in recent years. Closed coal mines refer to the permanent termination of production activities by a mine or mineral processing plant after completion of the shutdown process and marked by the cancellation of the lease. ${ }^{[3]}$ On the basis of the reasons for mine closure, it can be divided into policy closed coal mines, closed coal mines due to safety or benefit problems, and resource depleted closed coal mines. The environmental control and ecological restoration of closed coal mines mainly include the geological disaster treatment of the mine area, the restoration of surface water and groundwater quality, the restoration and reclamation of soil, the reconstruction of biodiversity, and the construction of regional landscape and functional facilities. The ultimate goal is to restore the closed coal mines to an area with a specific production function, which is acceptable to the society and the public - without the risk of environmental pollution. The concrete and quantifiable indices include comprehensive control rate of soil and water loss, detection index of "three wastes," vegetation coverage rate, biodiversity index, land reclamation rate, the utilization rate of mine remaining facilities, the utilization rate of mine water resources, and utilization rate of tailings.

\section{Policy development related to environmental governance and restoration of closed coal mines}

Since the 18th National Congress of the Communist Party of China, General Secretary Xi Jinping has put forward the idea that landscape, forest, lake, and grass are communities of life from the macro perspective of ecological civilization construction. In October 2016, the Ministry of Finance, the Ministry of Land and Resources, and the Ministry of Environmental Protection jointly issued the "Notice on Promoting the Ecological

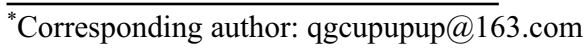


Protection and Restoration of Mountains, Waters, Forests, and Lakes." This issued notice put forward clear requirements for the implementation of environmental protection and restoration of mountains, rivers, forests, and lakes in various regions. Overall, the repair governance provides ideas and guidance.

Since 1989 , the state has gradually carried out land reclamation work, especially in the past five years. With the country paying attention to environmental governance, many subdivision areas of management measures have been issued. In 2015, the "Management Measures for the Pilot Management of Reclamation and Utilization of Abandoned Historical Industrial and Mining Lands (National Land Resources Regulations) [2015] No. 1" documented the reclamation of abandoned industrial and mining land by linking it with new urban construction land and adjusting the layout of construction land. A previous study ${ }^{[4]}$ clarified that the development direction of the above closed coal mine governance is to solve the contradiction between insufficient funds for land reclamation and lack of space for urban construction. The state invested a huge amount of funds to compensate for the implementation of such projects. The "Guidelines for the Entry of the Reserve Bank of Key Central Ecological Protection and Restoration Fund Projects (2020)" mentions that the projects entered are mainly used for the governance and restoration of the history that the main body of responsibility has been lost or cannot be determined. Afterward, the government must assume governance responsibilities over the related problems, such as destruction of topography and landscape, land occupation and destruction, destruction of groundwater aquifer, and degradation of ecosystems in abandoned mines.

Coal mines policy timeline of China

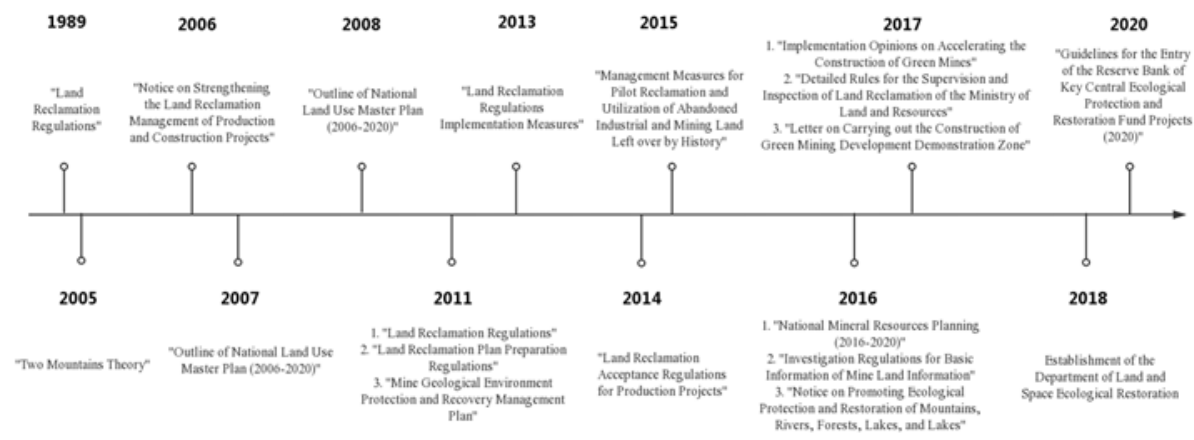

Figure 1. Coal mines policy timeline of China

\section{Key technical difficulties for environmental management and restoration of closed coal mines}

The technical problems of environmental management and restoration of closed coal mines mainly include the following aspects:

(1) Land damage: The mining of mineral resources inevitably encroaches on many lands and discharges solid waste. The damage to the land by coal mines is mainly manifested in the pollution of the soil and water bodies by heavy metal elements leached out after the coal gangue is compressed by the ground, and the land is occupied by the coal gangue.

(2) Geological disasters: After the mine is closed, hidden dangers of geological disasters still exist. These hazards include exposed waste rock in the stope and dumping site, weathering of rock and soil, landslides caused by no vegetation cover on slopes, soil erosion, dust and sandstorms caused by resource mining, pollution, residual deformation, surface subsidence, collapse, and even induced earthquakes in old coal mines and old roadways.

(3) Environmental pollution: Mining leads to the destruction of groundwater resources, and the discharge of mine water creates new pollution to the surrounding environment of the mining area. The closure of mines also caused air pollution problems, which are mainly manifested in old stopes, old roadways, residual coal pillars, and residual coal from gangue hills. They are also evident with the presence of other harmful gases, such as carbon monoxide, sulfur dioxide, and methane due to oxidation and spontaneous combustion. ${ }^{[5]}$

Different from general environmental governance issues, for the coal mines, the destruction of the geological environment is the root cause of the destruction of the surface ecological environment. One of the common mine environmental problems in underground mining is mining subsidence. The mine environmental effects induced by mining subsidence are mainly manifested in physical damage to landscape, land, soil, vegetation resources, and aquifer structure. ${ }^{[6-7]}$ According to its formation mechanism, mining subsidence can be divided into two categories: continuous subsidence and rupture subsidence, in which the main surface characteristics of continuous subsidence are subsidence basins. Environmental control of coal mining subsidence area is a key problem in the direction of environmental control and restoration of closed coal mines. At present, the treatment of coal mining subsidence wetland is mainly through the adoption of water quality purification, water system connectivity, basement transformation, phytoremediation, and 
landscape design. In this way, coal mining subsidence wetland becomes a stable wetland ecosystem with excellent water quality, beautiful landscape, and various functions. In recent years, the planning and management direction of coal mining wetland in China is mainly wetland park, aquaculture, reservoir, and constructed wetland sewage treatment system. ${ }^{[8-9]}$

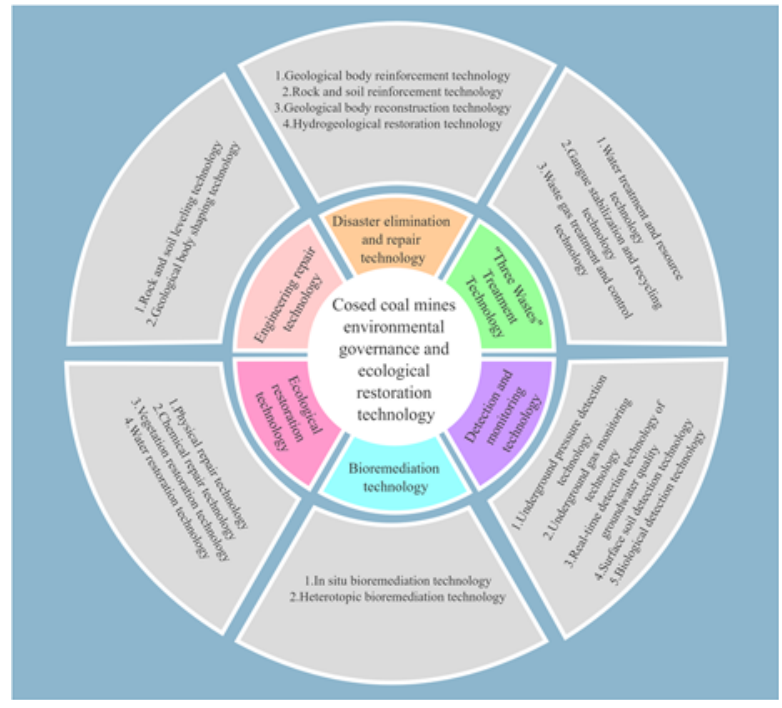

Figure 2. Technical methods for closed coal mine restoration

The problem of geological disasters should be taken as the premise to control the environment and ecology of closed coal mines. Therefore, environmental technology companies with geological engineering backgrounds are fit for this field. Six kinds of treatment technologies can be used for closed coal mines: disaster elimination and restoration technology, engineering restoration technology, ecological restoration technology, "three wastes" treatment technology, bioremediation technology, and environmental detection and monitoring technology. Enterprises or third-party environmental technology companies usually adopt these six types of technologies in concert. Then, they select specific process routes in accordance with specific working conditions to conduct long-term management and monitoring of closed coal mines.

\section{Economic and environmental benefits of environmental treatment and restoration of closed coal mines}

The environmental and social benefits of closed coal mine treatment are obvious. Some closed coal mines can be transformed into grasslands, forests, landscape parks, and artificial lakes (wetlands). However, less land is converted into construction land or residential land. The construction cost and construction cycle of geological hazard management are much higher than that of general industry "three wastes." Thus, the non-technical core problem of environmental treatment and restoration of closed coal mines is that the cost is too high, and the period is too long. Moreover, the effect is slow, and the direct economic benefit is not obvious.

According to the principle of "who pollutes who governs," the ecological restoration of closed coal mines should be spearheaded by mine production (mining) enterprises. However, the management of closed coal mines has no economic benefits for enterprises and consumes considerable human and financial resources. Therefore, the enthusiasm of enterprises is extremely low. Most of the current governance projects are conducted by the mining government and procurement governance services, which manage the implementation of these projects.

In the early years, the "mine environmental governance and restoration deposit" system was adopted to ensure that mining enterprises implemented environmental governance and restoration actions for closed coal mines. However, from a practical point of view, the "margin system" has some problems. For instance, the margin charge standard is low, which does not meet the actual needs of the ecological and environmental protection and governance restoration of the mines. The payment form is only cash, which is not conducive to the capital turnover of enterprises and increases the burden on them. As well as the restoration management plan for the mining environment, acceptance criteria and acceptance procedures, and deposit return procedures, the plan deviates greatly from the actual situation.

In 2017, in accordance with the State Council's "Notice on Printing and Distributing the Reform Plan of the Mineral Resources Equity Fund System" (State Council [2017] No. 29), the Ministry of Finance worked with the Ministry of Land and Resources in conjunction with the relevant requirements of the State Council on "Adjusting the Mine Environmental Governance and Restoration Deposit to the Mine Environmental Governance and Restoration Fund." The Ministry of Natural Resources researched and drafted the "Guiding Opinions on Canceling the Deposit for Mine Environmental Governance and Recovery and Establishing a Mine Environmental Governance and Recovery Fund (Department of Economic Construction, General Office of the Ministry of Finance [2017] No. 73)." This reform involves the direct rights and interests of mining enterprises. It mentions the cancellation of the guarantee deposit system, wherein the mining enterprises no longer set up special deposit accounts for deposits. It also clarifies the responsibility of the enterprises regarding mine environmental governance and restoration. After the deposit is canceled, the enterprise shall bear the responsibility of restoring the mine environment and raising funds for governance restoration through the establishment of funds. According to statistics, in the past five years, the central government has invested 100 billion yuan in environmental management funds for coal mine closures.

Some successful cases of mine management and restoration in foreign countries are relatively early. The Akashi Strait Park in Japan and the Biville recreation area in France are well-known examples of restoration cases. The InterContinental Shanghai Sheshan Shimao and the East Lake Scenic Area in Shaoxing in Zhejiang have become famous Internet celebrity punch cards. Tangshan Nanhu City Central Ecological Park is also a 
well-known case of mine closure and mine restoration. Its predecessor was a huge coal mining subsidence area. After nearly 20 years of continuous transformation, it has become a national AAAA-level scenic spot. The restoration process is divided into four stages: survey to determine the area and impact range of the collapse during the planning period, topography and soil improvement, water system improvement, and landscape ecosystem construction. Given the closure of small coal kilns in Hebi Heshan District of Henan Province, the economy once declined, and the population was seriously lost. At the same time, many abandoned mines need to be treated. The main mine geological environment problems are coal gangue stacked at will in coal mining and ground fissures affected by goaf, land subsidence, land resources, and topographic and geomorphological landscape. Aquifer damage, rock mass loosening and serious ruptures, high and steep slopes formed by mining, incomplete mountain body riddled with holes also result in dangerous cliff rocks and a series of mine geological environment problems. In recent years, the district government has vigorously restored closed coal mines by applying for state funds and introducing social capital. A total of $57.90 \mathrm{hm}^{2}$ of cultivated land has been restored using the measures of expert demonstration of geological status and ecological environment status, control of geological hazards, slope stability, and surface greening. Mine water treated up to standard in coal production was also introduced as a water supply that restored $12.48 \mathrm{hm}^{2}$ of forest land. Consequently, the environment has improved, the population of the district has increased annually, the economy has gradually recovered, and the overall social benefits are better than before.
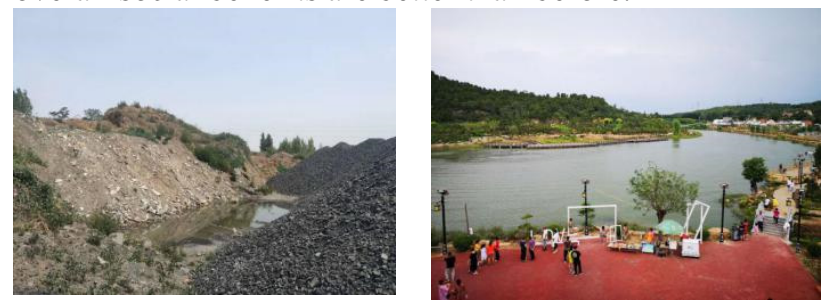

Figure 3. Comparison before and after repair

\section{Experience and prospect of environmental treatment and ecological restoration of closed coal mines}

In the 20 years since the "Regulations on Land Reclamation" was promulgated, China has conducted considerable research and practice of reclamation technology, mainly in the mining areas with the high water level in the east. In the past ten years, the research on the treatment of coal mining subsidence in the west has received attention and achieved rapid development. In coal mine reclamation, five out of the seven National Science and Technology Progress Awards have been produced around the western mining areas in the past decade. As the country pays increasing attention to ecological and environmental protection, it has carried out technical research on the construction of urban landscape wetlands on damaged land in mining areas.
The government also has established pilot projects in many areas, achieving good results.

The key to environmental treatment and environmental restoration of closed coal mines is the treatment of geological disasters and ecological environment, so its treatment cycle is long and difficult. The goal of restoration and treatment is not to restore the same environmental conditions as before mine development. Instead, it aims to establish an enduring regional system with stable environmental indicators up to standard and ecological harmony on the basis of stabilizing the current geological conditions. It also hopes to restore the other functions of the region.

Although the direct economic benefits of environmental management and ecological restoration projects are not obvious, the value of the restored land can be used as a condition for the government to introduce social capital and mobilize the enthusiasm for restoration. Therefore, local governments are advised to explore new models of collaborative functional development of mine environmental management and ecological restoration.

\section{References}

1. Ren Xuefeng. A Study on the Resilience of the closed coal mines Social Ecosystem in Eastern China [D]. China University of Mining and Technology, 2017.

2. CCTV. Emergency Management Department: Eliminate and close small coal mines by 2022, large coal mines account for more than $70 \%$. [EB/OL]. https://news.china.com/domesticgd/1000 0159/20200428/38152260 all.html,2020-4-28.

3. Liu Changhua. Mine closure planning [M]. Xi' an Map Publishing House,2005.

4. Hu Zhenqi. 30 Years of Land Reclamation and Ecological Restoration in China: review, reflection and prospect [J]. Coal Science and Technology, 2019, 47(1): 25-35.

5. Guo Youhong, Wang Shuli. Analysis on Current Situation and Countermeasures of Sustainable Development of Closed Pit Mine [J]. Mines Surveying, 2013(05):90-91+99.

6. Wu Qiang, Chen Qi. Environmental Effects Induced by Mine Environmental Problems [J]. Hydrogeology \& Engineering Geology, 2008, 35(5): 81-85.

7. Wu Qiang, Chen Qi. Analysis of Management Model and Applicability of Mine Environment [J]. Hydrogeology \& Engineering Geology, 2010, 37(6): 91-96.

8. Wang Zhenlong, Zhang Qibing, Li Rui. A Study on the Utilization of Rain Flood and Ecological Restoration in Coal Mining subsidence Area [J]. Journal of Natural Resources, 2009, 24(7): 1155-1162.

9. $\mathrm{Fu}$ Yanhua, $\mathrm{Hu}$ Zhenqi, Xiao $\mathrm{Wu}$, et al. Coal mining subsidence wetland and its ecological control [J]. Wetland Science, 2016(5): 671-676.

10. Liu Qingfang. on the Implementation of the Deposit System for the Closure of Mining Enterprises 
Geology of China [J]. Geology in China, 1996(12):28-29.

11. Yan Shouguang, Shen Weishou, Zou Changxin. China
Mine Environmental Management Restoration Deposit System [J]. Environmental Science and Management, 2012, 37(6):1-4. 